\title{
TOURISM INNOVATION POLICY: IMPLEMENTATION AND OUTCOMES
}

Rodriguez, I., Williams, A. \& Hall, C.M. 2015, Tourism innovation policy: implementation and outcomes. Annals of Tourism Research, <DOI:10/1016/j.annals.2014.08.004>

[Submitted draft of paper. For the authoritative version, please consult the journal]

\begin{abstract}
The paper opens the "black box" of tourism innovation policy implementation through an analysis of the Spanish Programme of Innovative Business Groups that foster innovation through hybrid top-down bottom-up collaboration embedded in clusters. The focus is on three main issues: process of policy implementation, types of innovation that emerged, and the outcomes and barriers. The findings show the contradictions of this hybrid model of implementation with mixed outcomes of successful collaborations and abandoned trajectories. The Programme has stimulated the 'propensity' to innovate resulting in different types of innovation but has revealed the existence of mutually-reinforcing barriers. Some suggestions for future improvements of tourism innovation policies are offered including the importance of polycentricity in effective policy formulation and implementation.
\end{abstract}

\section{KEYWORDS}

Innovation policy, policy implementation, innovations, polycentricity, barriers, Spanish Innovative Business Group 


\section{INTRODUCTION}

Innovation concepts have gradually percolated into the tourism literature but research on tourism innovation policies has been limited (Hall \& Williams, 2008; Hall, 2009a; Hjalager, 2010, 2012). The linked concept of tourism clusters (Weidenfeld et al., 2010; Nordin, 2003; Jackson \& Murphy, 2006; Hall, 2005; Michael et al., 2006; Novelli et al., 2006; Weidenfeld \& Hall 2014) has been more extensively researched, although it focuses more on spatial proximity and cooperation than on the functioning and outcomes of territorial innovation systems. This situation reinforces Hjalager's (2012: 337) assessment that research on tourism innovation policies remains 'extremely fragmented and largely ignored', potentially reflecting the persistent isolation of tourism from innovation policy and innovation systems discourses (Hall, 2009a; Keller, 2006). It constitutes a striking omission because innovation policies potentially can address systemic failures and institutional and behavioral barriers to innovation processes (Edquist, 2001) which lie at the heart of competitiveness and performance enhancement in a sector with relatively low rates of innovation. Moreover, existing reviews of tourism innovation policies (Hall \& Williams 2008; Hjalager 2012) have highlighted their highly uneven performance, underlining the need for research in this arena which provides a more critical assessment of the potential.

The limited literature on tourism innovation policies has largely been conceptual or prescriptive, with relatively little empirical evidence about outcomes and effectiveness (Hjalager, 2010). Despite this research gap, tourism innovation policies are increasingly extolled as integral to tourism sector and destination development (OECD, 2006, 2012a; Mei, Arcodia, \& Ruhanen, 2013), although such assertions are not always firmly evidence based. In responding to the need for detailed evaluation of tourism innovation policy implementation (Hall \& Williams, 2008), this paper addresses Spain's R\&D\&i Plan, 2008-2011. This policy identifies tourism as an objective of sectoral innovation, and the Programme of the Innovative Business Groups (Agrupaciones Empresariales Innovadoras [AEI]) for small and medium sized enterprises (SMEs) is a rare example of tourism being funded as part of a national innovation programme. The focus on SMEs also reflects their prevalence in most tourism sub-sectors, and their specific contribution to shaping tourism innovation (Hall \& Williams, 2008; Hjalager, 2010; Alsos, Eide \& Madsen, 2014).

The paper focuses on three main issues. First, the hybrid top-down and bottom-up policy setting. Although initiated at the national level, implementation was expected to be at ground level, via clusters of collective actors with firms playing a pivotal role. Tourism partnerships tend to depend on public sector actors and often exhibit 'partnership fatigue' (Caffyn, 2000; Zapata \& Hall, 2012). This is particularly relevant where, as in the AEI Programme, partnership incentivisation was top down, and there were substantial implementation barriers. An important exogenous constraint is that the AEI was born in a positive economic era but implemented as the 2008 economic crisis unfolded with particular severity in Spain. The Spanish government's response to the crisis led to sharp reductions in public expenditure, including the AEI Programme. This constituted a particularly severe testing ground for the efficacy and sustainability of attempts to foster innovation through hybrid top-down bottom-up collaboration (Plummer, Kulczycki \& Stacey, 2006). Secondly, innovation is understood in terms of the generic definition of 'the generation, acceptance and implementation of new ideas, processes, products or services' (Kanter, 1983: 20-21), while acknowledging that tourism innovation has

distinctive features including a focus on co-terminality of production and consumption, 
information intensity, and the complex nature of the tourism product (Hall \& Williams, 2008: 1118). This definition frames an examination of the types of innovations (Adams et al., 2006) that emerge during ground level implementation of policy and the extent to which these are 'distinctive' features of tourism innovation. Thirdly, the paper therefore provides one of the few detailed studies of innovation policy outcomes in tourism. Most policy evaluations, if they occur at all, are made too early after their initiation (Sabatier, 1986). The Spanish Programme had been in operation for six years at the time of this research, making it possible to give an informed commentary on implementation barriers, processes and outcomes. The barriers also highlight some of the specificities of tourism production which represent particular challenges for developing effective tourism innovation policies. This therefore provides a unique longer-term perspective on innovation in tourism across a specific policy initiative. The outcomes are considered not only in material and financial terms, but also innovative capacity and culture, and innovation propensity (Mohnen \& Röller, 2005). The article considers these three themes after first reviewing the research literature, explaining the methodology, and outlining the main features of the AEI Programme.

\section{CONCEPTUALIZATION}

\section{Systems of Innovation and Innovative Clusters}

There is increasing attention to the role of national and regional innovation systems, which embrace R\&D, technology, infrastructure, and education policies, as well as demand side measures (Braczyk, Cooke, \& Heidenreich, 1998; Hall \& Williams, 2008). The innovation system approach has been promoted or applied in several policy contexts by national governments and regional authorities, as well as international organizations such as the OECD and the EU (Edquist, 2005). It emphasizes interdependence and non-linearity, and that innovation involves firms interacting with other organizations through complex relationships that are embedded in local, national and international structures (Lundvall, 2007; Weidenfeld \& Hall, 2014). The state is a core actor in this complex relational system, with capacity to intervene to achieve policy goals, especially when market mechanisms fail to achieve desired aims (Edquist 2005; Hjalager, 2012). It can also remove barriers to innovation, and provide resources and regulatory incentives (OECD, 2001), as well as co-financing to stimulate private investment and public-private collaboration (OECD, 2009). Ideally, effective state policies and instruments should be aligned and self-reinforcing (OECD, 2012b). However this is harder to achieve in relatively nebulous and cross-agency policy areas such as tourism (Hall, 2009a).

Local and regional innovation systems are the organizations and institutions that produce, distribute and utilize knowledge within a region (Hall \& Williams, 2008). Because the innovation system is influenced by territorially distinctive institutions (Asheim et al., 2011), and interactions and learning are variable across localities (Tödtling \& Trippl, 2005), the sub-national level is a key site for innovation policies (Gertler, 2000). Hjalager (2012) emphasises the importance of sub-national territorial innovation systems in tourism. However, industry and sectoral innovation systems, such as those that may be associated with tourism, may cut across local and national innovation systems and encourage international learning and networks (Weidenfeld \& Hall, 2014). 
Clusters have been promoted because of their potential to function as a specific form of innovation system (OECD, 2001). Agglomeration and localization economies can increase competitiveness and innovativeness, while stimulating competition and co-operation (Malmberg \& Maskell, 2002; Porter, 2000). They potentially reduce production factor costs and risks, thereby reducing transaction costs, and facilitate learning via socially embedded linkages between firms (Malmberg \& Maskell, 2002; Wolfe \& Gertler, 2004), although the overall importance of proximity in knowledge transfer remains contested (Amin, 2002). Nevertheless, policy discourses emphasise the role of spatial proximity within clusters as facilitating networking, collaboration, and knowledge transfer in tourism innovation (Weidenfeld et al., 2011).

There are important qualifications about clusters as innovation systems. First, they tend to be rooted in institutions and location-specific resources which have evolved organically, and are not easily transferable between places (Longhi \& Keeble, 2000), especially in tourism (Hall \& Williams, 2008). Second, key elements in regional innovation systems may be determined externally, such as infrastructural, corporate, or education investments, emphasizing the importance of a multi-scalar approach. Thirdly, the performance of regional innovation systems is highly variable reflecting differences in firms' innovative and relational capacities, institutional quality, and policy orientation (Tödtling \& Kaufmann, 1999). Nevertheless, in tourism the longer-term trajectories of local and regional innovation systems that have received substantial external stimulus, for example because of major state innovation support programmes such as AEI, have not previously been examined.

\section{The Implementation of Tourism Innovation Policies}

Implementation implies a linkage between policy and action (Barrett \& Fudge, 1981). Tourism policy and implementation are, therefore, two sides of the same coin (Hall, 2008). Research from the policy field (e.g. Birkland, 2005) suggests that approaches to implementation can broadly be categorized into three archetypes: 'top-down', 'bottom-up' and 'interactive' or 'hybrid', with the first two categories often being utilized in the tourism literature (Hall, 2009b).

From a top-down perspective implementation is conceived as the hierarchical execution of centrally-defined policy intentions (Puilzl \& Treib, 2007), whereby policies are introduced from above and are implemented by those at the "bottom" of the hierarchy. This archetype suggests that it is possible to distinguish between policy and implementation, and between policy actors that mobilize government resources to achieve policy goals and policy implementation agents that receive these resources to achieve policy outcomes (Flanagan et al., 2011). Although a hallmark of formal considerations of the policy-action relationship, the model fails to consider the ongoing role of other actors and interests as well as the distribution of power in crowded 'policy spaces' in which implementation occurs (Majone, 1989). In contrast, the bottom-up approach emphasizes that top-level policy, legislation and regulation are often poorly connected to what actually happens on the ground (Hjern, 1982). In part this is because of potentially conflicting, competing and overlapping policy objectives that can occur through multiple layers of decision-making (Sabatier 1986; Hupe, 2011, 2014). A bottom-up approach suggests that in reality policy is made through practice, that is through implementation actions which determine policy outcomes (Barrett \& Fudge, 1981). Nevertheless, bottom-up approaches also have their 
critics, with Ostrom (2005), for example, emphasizing the need to recognize the power wielded by the centre in distributing resources and shaping institutions.

Both the top-down and bottom-up frameworks over-simplify the complexity of implementation and the polycentric nature of much policy-making (Toonen, 2010), especially in the European context (Faludi, 2008; Newig \& Koontz, 2014). A third, hybrid approach therefore emphasizes the complex negotiations and bargaining between policy actors at all levels of the policy process (Hall, 2009b). Indeed, there is a false dichotomy between bottom-up and top-down approaches that operate simultaneously. Implementation is top-down to the extent that legislation and regulations constrain the power of those below but lower-level policy actors also take decisions which effectively limit hierarchical influence, pre-empt top-down decision making, or alter policies (Barrett \& Fudge, 1981).

Polycentricity is an intellectually broad concept that stresses the need for and the importance of multiplicity, diversity, interdependency, checks and balances, complexity, and requisite variety in both the study and operation of public policy delivery (Andersson \& Ostrom, 2008; Tonnen, 2010). Although the significance of such polycentric policy-implementation relationships has been recognized in the public administration literature since the early 1960s (e.g. Ostrom, Tiebout \& Warren, 1961) its implications for tourism policy implementation has been little considered, despite its intellectual legacy of network governance (Hall, 2011). Polycentric theories of policy implementation resonate with some of the observations made in this article as there are overlapping policy jurisdictional relations of inter-organisational and intergovernmental dynamics within a multi-faceted innovation policy environment. In other words, when policy matters are neither fully reserved nor devolved, cooperation among organisational units of central and devolved governments is important to the effectiveness of policy formulation and implementation (Fyfe, Johnston Miller \& McTavish, 2009).

From a polycentric perspective effective implementation is dependent on cooperation across organisational units, but the likelihood of this being achieved will be limited if the political authority of any of the different units is weak or absent. Cooperative effort depends on the composition and alignment of strategic variables, including policy characteristics, interorganisational structures, knowledge and modes of problem-solving (Hanf \& O'Toole 1992). Moreover, policy characteristics themselves determine certain features of the relationship between policy actors that affect the opportunities for collective action (Fyfe et al., 2009). Furthermore, the levels of interdependence between policy actors determine the loci of power within the system and the level of coordination. Differences in decision-making styles, for example between public and private partners in innovation clusters, will also affect problemsolving capacity within polycentric structures and influence cooperative implementation efforts. 'Information such as perceptions of others' actions and the channels for the flow of information within polycentric arrangements are important in developing commitment across organisational boundaries and influencing perceptions which may unnecessarily inhibit implementation or achieving a common purpose' (Fyfe et al., 2009).

Polycentric perspectives on the policy-action relationship have particular relevance for understanding cluster policies (OECD, 2001). The evidence on the effectiveness of top-down versus bottom-up clustering is indeterminate, and based on hazy evidence about outcomes. There are exponents of the relative effectiveness of both bottom-up and top-down approaches, but the 
effectiveness of the two approaches appears contingent on regional institutions and cultures (Fromhold-Eisebith \& Eisebith, 2005), including with respect to tourism (Nordin, 2003).

\section{Outcomes and the focus of innovation policies}

Innovation is a focal point of economic policies because of its perceived contribution to competitiveness. Most innovation is incremental rather than radical, especially in tourism, but radical 'changing the rules of competition' innovations are regarded as providing significant competitive advantages and have therefore become a focus of state policy interventions. Process, supply-chain led and organizational innovations (OECD, 2005a), and the complex interaction amongst the agents and agencies that collectively produce the tourism experience, are particularly important in tourism innovation (Hall \& Williams, 2008; Hjalager, 2002; Jacob et al., 2003). Technological innovations are also promoted as important. Yet it is unclear whether the implementation of broad policy goals has enabled tourism innovation specific outcomes.

Measuring innovation and cluster policy outcomes, many of which are intangible, poses difficult challenges (Diez, 2001), as they involve both material output and qualitative changes in the behavior of companies, policy actors and institutions. There is also no simple linear cause-effect model of the relationships between inputs/activities and outcomes. The challenges of assessing the outcomes of tourism innovation policies are even greater in tourism innovation systems, given the complex inter-relationships between diverse sets of actors (Hall, 2008). Except in very limited circumstances, it is extremely difficult to assess the proportions of increased outputs or sales that are due to a specific set of innovations distributed across varyingly inter-related firms (Smith, 2005). There are similar difficulties in assessing the effects of clusters on innovation performance. Fromhold-Eisebith and Eisebith (2005: 1251) conclude that '...the crucial task of evaluating impacts of cluster support, discerning strategies that achieve the best results depending on preconditions, has hardly been addressed due to the intricate methodological complexities involved'. Moreover, similar policies can result in different outcomes in particular localities (Benneworth et al., 2003), not least because of different barriers to implementation.

Generic assessments of barriers to innovation include resources (lack of time, finance, or knowledge), risk aversion, resistance to change, over-hierarchical structures, fears of new technology amongst staff and customers, bureaucracy, traditional thinking, lethargy, and short termism (Hall \& Williams, 2008; Hjalager, 2012). Such barriers contribute to the suggestion that tourism firms tend to be late adopters, 'gap-fillers' and imitators (Ioannides \& Petersen, 2003; Jacob et al., 2003; Hjalager, 2010). This clearly raises further questions about the extent to which broad top-down initiated innovation policies can, at the implementation stage, be translated into effective measures to remove barriers to innovation in individual tourism clusters, destinations, and firms.

\section{METHODOLOGY}

Although secondary sources, such as the Community Innovation Survey (Eurostat 2014), provide some data on firm innovation, there are no such sources on tourism innovation policies, or their outcomes. Researchers seeking to address this gap via primary data collection require access to high-level policy makers, and this research had privileged access to key decision-makers in 
Segittur, the tourism innovation state owned company that manages the AEI Programme for tourism. Given the focus of this paper on the instrumental and operative dimensions of tourism innovation policies, a qualitative approach allows the specificities and nuances of the tourism innovation policy process and outcomes to be addressed. The originality of this study lies on a monographic evaluation of a tourism innovation programme, involving interviews and documentary analysis at different levels within the policy framework, and reviewing the full life cycle of some of the projects.

Segittur provided internal documents relating to programme management and funding allocations to individual AEIs, 2008 to 2012. These include evaluation reports with detailed summaries of every one of the 59 actions/projects funded, which allowed the production of summative quantitative data about innovation investment, the actors involved and the types of innovation addressed by the projects. They did not provide sufficient information on the effectiveness of the outcomes, or the factors which influenced these. The researchers therefore also undertook semistructured interviews, via Skype, with management representatives of tourism AEIs in November and December 2012. 28 AEI managers from the 33 officially listed on the Ministry's Special Registry agreed to participate. Of the remaining five, three refused to be interviewed, and two were too recently established. Face-to-face interviews were also undertaken with the two key decision makers responsible for the programme within Segittur. The standardized nonprogrammed formats of the interviews allowed a flexible approach to explain the complexity of innovation processes involving a multiplicity of actors and an extremely heterogeneous AEIs ecosystem. The interview recordings were transcribed and qualitatively analysed using the open and axial codification process (Strauss \& Corbin, 1990) and Atlas.ti software. This involved data reduction through codes application, categorizing and selection of recurring themes. Quotes from the transcriptions are used to support and illustrate these themes in the analysis section. Most interviewees provided copies of their strategic plans. Interviews lasted one hour on average.

Despite the privileged access to actors at different levels within the programme, a number of limitations of this approach are acknowledged including the subjective nature of the interviews, coverage of only part of the project life cycle in many instances, and only limited access to the multiple informal relationships and contacts which provide the essential "glue" in the policy formulation and implementation process. Nevertheless, the comments of the AEI managers were triangulated with those responsible for overall supervision of the AEI Programme for tourism within Segittur, as well as the documentary materials, in order to provide a perspective on the necessarily subjective nature of interview data. The research on the AEI Programme is a case study of one, relatively well-developed tourism innovation policy initiative that has sufficient trajectory for evaluation and, as such, it provides insights into policy implementation and outcomes. Given the socially situated nature of any such policy, and especially its institutional specificity, the findings are not directly applicable in other national contexts, but they do highlight key issues, contradictions and conflicts that shape both implementation and outcomes determined by the specificities of innovation in tourism. These are further discussed in the conclusions.

The research was subject to approval under the lead university's code of ethics, and is based on the voluntary informed consent of participants to use their opinions and the documentary data provided, while assuring the anonymity of individuals. 


\section{TOURISM POLICY AND INNOVATION POLICY IN SPAIN: THE AEI PROGRAMME}

The Spanish Tourism Plan Horizon 2020 (SGT, 2007) was Spain's first tourism policy substantially addressing innovation. It focused particularly on how to overcome the perceived barriers to tourism innovation, such as a predominance of SMEs, low investment levels, lack of creativity and entrepreneurship, and retention of human capital, via three specific Programmes: Innovation, Knowledge and Talent attraction. Tourism was also recognized in the national innovation policy, the R\&D\&i National Plan 2008-2011, as a sector that should 'promote a continuous dynamic of innovation and technological development' (p.75). However, no specific strategies or actions were proposed for tourism.

Although there is a significant disconnect between the tourism and innovation policy arenas, tourism authorities did perceive an opportunity to participate in the AEI. Based on a cluster approach, this Programme aimed to promote innovation and competitiveness in (by 2013) some 30 different sectors. The Tourism Plan Horizon 2020 incorporated the AEI Programme as a specific action to be implemented and promoted under the Tourism Innovation Programme. Segittur was appointed to manage the Programme for tourism: evaluating projects, assisting applicants, providing guidance and supporting existing AEIs. Tourism initially had its own budget, but was subsequently incorporated within the overall AEI budget.

The AEI Programme introduced a national cluster policy in 2007 to boost cooperation and facilitate knowledge exchange, creating linkages between industry, government, and universities. The AEIs were defined as 'a combination of businesses and public or private training and research centers in a geographic area or specific industrial sector involved in processes of collaborative exchange to obtain advantages and/or benefits from the execution of innovative joint projects' (AEI Base Regulatory Order 2691/2006, subsequently updated). The instrument provides financial support for four main types of actions:

a) Preparation of strategic plans.

b) Coordination, management, and administration of existing AEIs.

c) Development of specific projects to strengthen businesses' potential for innovation.

d) Promotion of joint actions and associated projects between Spanish AEIs as well as with groups or clusters in other EU countries.

Thirty-three tourism AEIs were established (declining to 21 by 2013), representing $13 \%$ of all AEIs. The Programme had several distinctive stages (Figure 1). In 2008, the first year of implementation, the focus was on developing strategic plans as these were compulsory requirements for the formal constitution of AEIs. The high level of resources available (maximum budget of two million euros) and the high percentage of proposals funded (23 of the 26 submitted) motivated a high level of participation. This led to a large numbers of proposals for strategic plans and individual projects being-presented in 2009, which necessarily meant greater selectiveness in implementation. By 2010, severe budgetary reductions meant that the Programme stopped financing strategic plans, and prioritized project development. After 2011 the formal agreement whereby Segittur managed the Programme was terminated, although it voluntarily continues to perform broadly similar functions. 
Figure 1 AEI Programme life cycle in tourism, 2008-2013

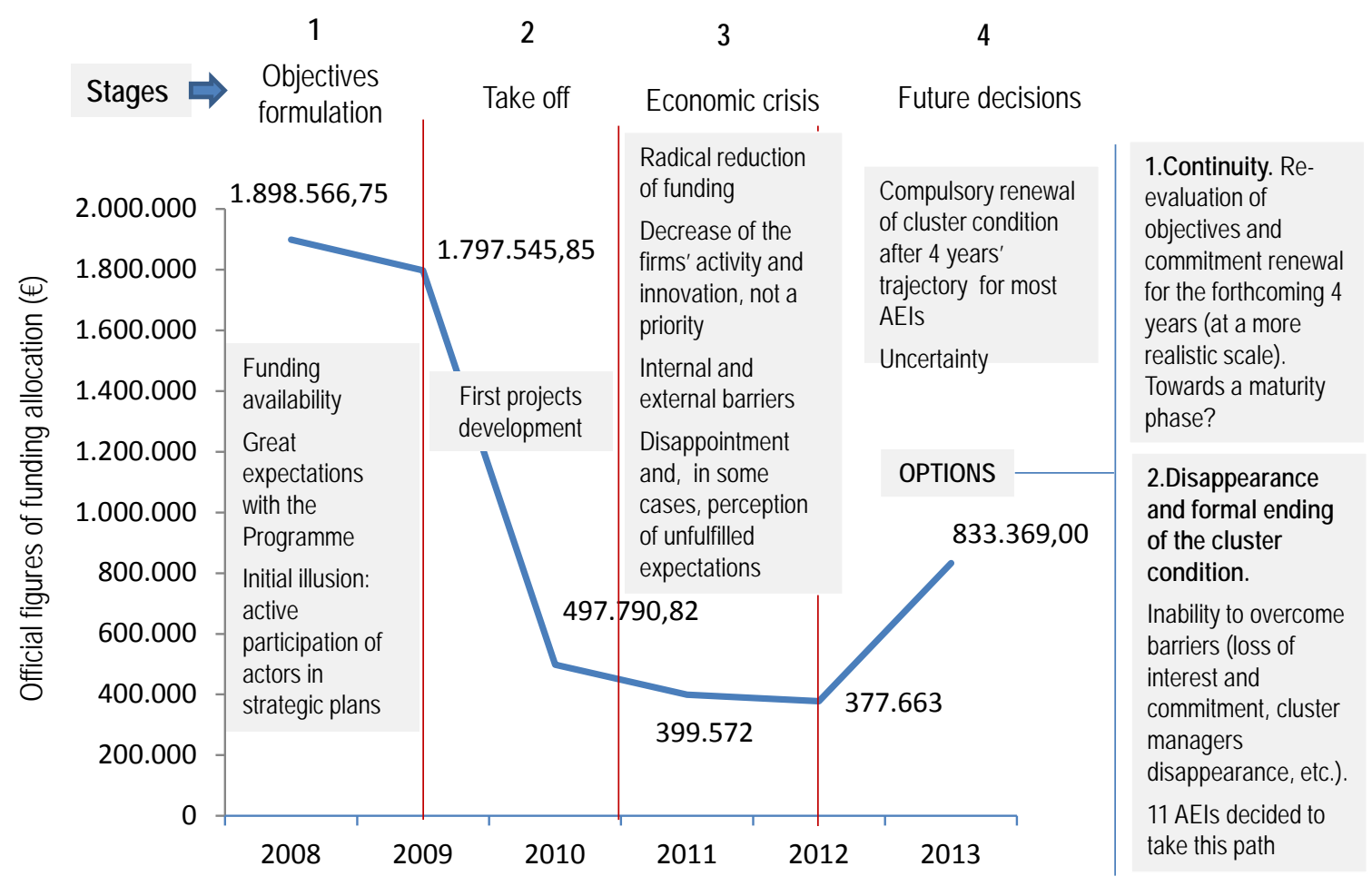

\section{ANALYSIS AND EVALUATION OF THE AEI PROGRAMME IN TOURISM}

\section{A bottom-up response to a government-driven programme}

Initially, Segittur's main role was to ensure the broad diffusion of the AEI Programme within the sector, with implementation being bottom-up, with clusters, and their innovation strategies and projects, supposedly emerging 'naturally' and organically. Figure 1 indicates the existence of a dedicated and apparently generous budget led to rapid creation of clusters, with the lead being provided by either regional governments or by consulting firms which realised the business opportunities these provided. This meant that strategies and projects tended to be developed for rather than by the participating actors. They were often over-ambitious and failed to capture the firms' real needs according to the interviews with the Segittur and AEI managers. Many of the (four year) plans also soon became obsolete in a deteriorating financial climate.

Figure 2 provides an overview of the main activities of AEIs. Enhanced networking has been the main task, especially intermediation between AEI members with potential synergies and common/complementary interests. Training activities or innovation competence building actions (work sessions and networking encounters) have also been common. Basic research linked to project development is the output most directly linked to innovation. Other actions relate to knowledge transfer. 
Figure. 2 Main activities developed by AEIs

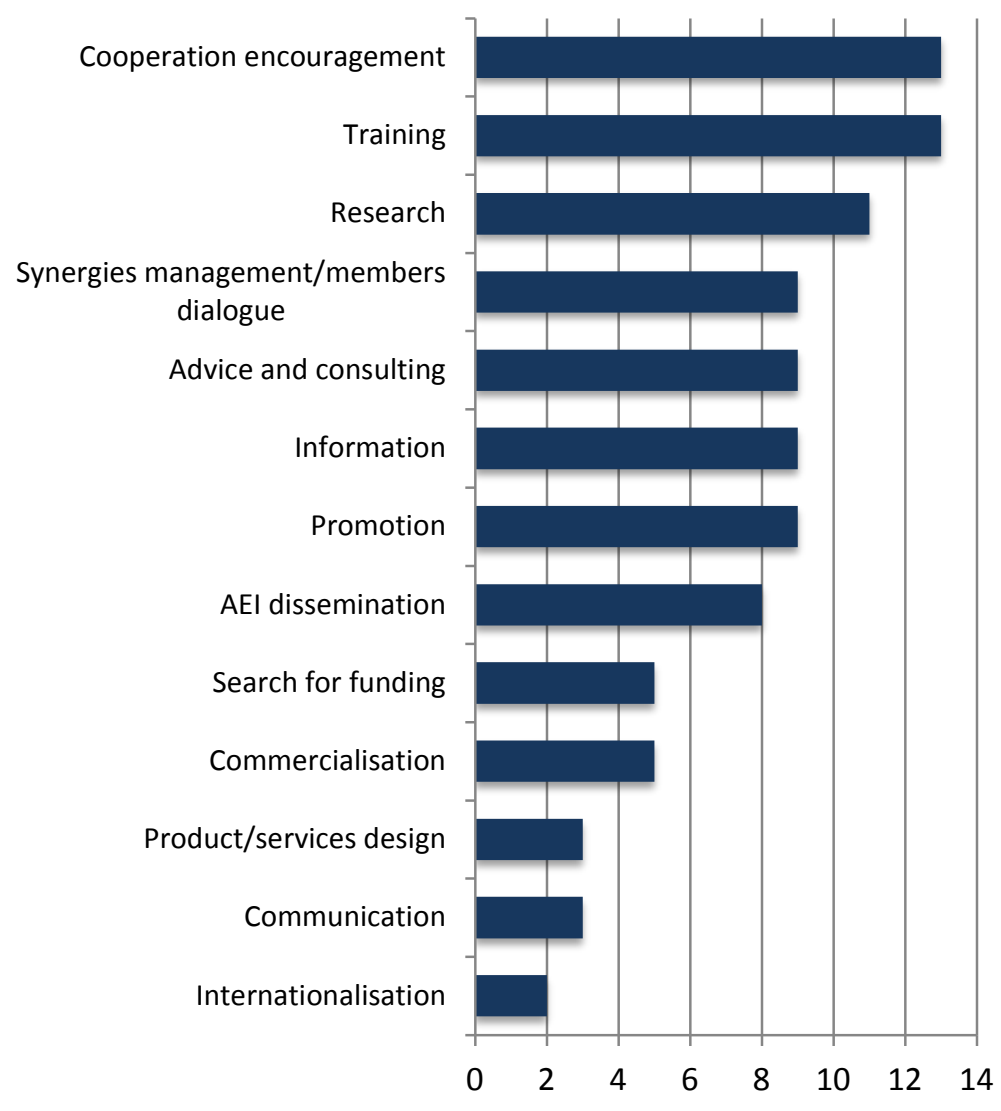

Total number of responses per item

Source: Authors’ interviews

Documentary evidence indicates that the implementation process has encouraged cooperation, especially amongst firms, consultancies and technology providers, in a sector where this has been relatively weak. This was informed by the AEI membership criteria, as well as the project evaluation criteria, which strongly emphasized collaboration. Inevitably, the level of involvement has varied across the AEIs' life cycles. The initial phase of cluster formation resulted in variable territorial outcomes, including formation of national networks, Autonomous Communities (Regions), groups of municipalities and localities. All of these pose different collaboration challenges, and resulted in variably effective networking and collaboration, according to the interviewed managers. Implementation was bottom-up, with a significant discretion in practices, contributing to divergence between policy intentions, outcomes and commitment to the AEI's activities. The AEI23 representative commented that: structures appeared 'forced', and collaboration lacked spontaneity, being driven by the political and strategic goals of the local and regional government partners rather than the private sector. Similarly, the AEI18 representative commented that: 
This cluster has had a top down impulse. It has not been created by the firms' initiative but instead by a public institution which considered this to be interesting...This wouldn't have been negative if later on the private sector had progressively been incorporated...something that never happened.

The cluster concept was usually more effective where there was a history of collaboration, or where there was a strong, shared territorial identity, evidenced in the interviews and project documents. Complementary roles amongst the actors, and a value chain approach, also facilitated stronger engagement and networking. However, the role of spatial proximity has, at best, been uncertain, perhaps reflecting the significance of the globalization of knowledge flows, and their interfolding with the local (Amin, 2002).

The effectiveness of networking also depended on resource availability. In most cases, the cluster managers who had formal contracts with the AEIs (ie. full-time paid roles) indicated that managing network relationships constituted a critical component of their activities (see Figure 2), whether amongst firms or with external suppliers. The interviews reveal that cluster dynamism was dependent on the individual managers' capacities to act as driving forces and sustain the members' interests. The absence of this formal structure, when public funding was withdrawn, usually led to disappearance of the AEIs (in nine instances) or to weaker collaboration. The documentary evidence also indicates that the main beneficiaries of the Programme and the most active partners were individual firms (especially consultancies and technology suppliers). However, even their engagement has been diluted because in most AEIs the firms have been represented by associations.

A potential weak point in the hybrid top-down bottom-up implementation lies in the central funding mechanism, especially the gap between the AEI guidelines and the funding criteria. Only $5 \%$ of the evaluation criteria are specifically allocated to innovation, and there is no specific guidance as to the types of innovation expected, e.g. type, short/long term horizon (AEI Base Regulatory Order IET/1600/2012). The evaluation criteria for specific and joint projects make more reference to innovation, research and technology but do not include systematic criteria to evaluate their innovativeness. There are also no binding criteria to guarantee the evolution of prototypes into fully implemented innovative projects. The relatively open, and unspecific, nature of the criteria increase the scope for subjective interpretations by both the applicants and the funding decision makers.

From policy to innovation practices

Between 2009 and 2012, policy implementation included the following:

1) Networking and fostering cooperation activities (six instances, project documents), including virtual networks amongst different AEIs and sectors. It includes the annual AEIs network meeting to promote collaboration amongst tourism AEIs.

2) Projects only involving basic research to identify market opportunities. These are usually exploratory studies prior to piloting or introducing new products and potential R\&D projects. They also explore links between existing products and tourism (e. g. music and tourism) or new concepts (e.g. an“ideal” water sports resort) (Table 1). 
Table.1 Basic research projects funded (2009-2012)

Studies and diagnoses

- Study of current regulation barriers to the development of innovative business in horse riding tourism

- Diagnosis, web site and reward system to encourage innovation in wine and gastronomy sector

- Music product reinforcement in Ibiza: innovation and cooperation between firms

- Strategic Research agenda with technological priorities for the tourism sector

- Conceptualization and research about an ideal water sport resort

- Planning exercise to create a real thermal product for a family segment

- Methodological basis for an e-learning platform to train employees for better job performance

Feasibility studies for experimental developments

- A hub of delay management between different agents of the value chain

- A real time carbon footprint monitoring system

- A European interoperability protocol for the tourism supply chain

- An online TV platform with tourism contents

Source: authors, based on AEI Programme documentation facilitated by Segittur

3) Three types of $R \& D$ projects involving a prototype development: never implemented, implemented at pilot stage, or achieving commercialization. Only the last of these, strictly speaking, represent actual innovation projects, and there have only been four instances. The projects have been further classified according to type of innovation (Table 2). The most frequent type of innovation was organizational (similar to Jacob et al., 2003), followed by product/service innovation and marketing innovation, while least common were process and other types (social/environmental) of innovation (see contrast with Hall 2009a). A discussion of each of the typologies in Table 2 now follows:

Table 2. R\&D projects by type of innovation

\begin{tabular}{|c|c|c|c|}
\hline $\begin{array}{c}\text { TYPE OF } \\
\text { INNOVATION }\end{array}$ & $\mathrm{N}^{\circ}$ & $\begin{array}{c}\text { TC } \\
*\end{array}$ & LIST OF PROJECTS \\
\hline $\begin{array}{l}\text { MANAGERIAL/ } \\
\text { ORGANISATIONAL } \\
\text { (FIRMS/TERRITORI } \\
\text { ES) }\end{array}$ & 11 & 11 & $\begin{array}{l}\text {-Technological platform for a global management of a language-learning schools network } \\
\text {-Collective information and services management for firms in the Pilgrimage Routes to Santiago } \\
\text { (contents management, new systems of payment, loyalty schemes, etc.). } \\
\text {-Web platform based on an integrated GIS system and GPS mobile device for the study of demand } \\
\text { mobility patterns, natural parks planning and management (Sierra de Gredos Natural Park pilot } \\
\text { project). } \\
\text { - Business intelligence system for rural accommodation firms with critical information for the decision } \\
\text { making } \\
\text {-Design of a tracking system and Hazard Analysis Critical Control Points (HACCP) for restaurants } \\
\text {-Identification of technological itineraries to incorporate innovation management in the business } \\
\text { planning of different subsectors (accommodation, restaurants, travel agencies, etc.). } \\
\text {-New customer relations management model for restaurants } \\
\text {-Tool development for an administrative and paperless management model } \\
\text {-Monitoring system to compare in real time competitors' rates } \\
\text {-System of hotel services evaluations by anonymous clients ('mystery guest' concept) } \\
\text {-Intelligent social network to reduce purchasing costs for tourism firms } \\
\text {-Management platform to integrate tourist resources as basic repository to create new products } \\
\text { - Cloud solution for SMEs to efficiently manage customer relations }\end{array}$ \\
\hline PRODUCT/SERVICE & 8 & 8 & $\begin{array}{l}\text {-WIFI platform to offer new services to golf course customers (email, restaurant and real time } \\
\text { booking, game information, etc.). } \\
\text {-Design and development of experiential products (pilot project in a restaurant). } \\
\text {-Mobile device App based on augmented reality and geolocation to associate information to natural }\end{array}$ \\
\hline
\end{tabular}




\begin{tabular}{|c|c|c|c|}
\hline & & & $\begin{array}{l}\text { areas } \\
\text { - iPad platform to integrate tourist contents and hotel services (5 hotels pilot project). } \\
\text {-Adaptation of a pilot tourist destination to disable tourists through mobile solutions based on NFC } \\
\text { (Near Field Communication) technology } \\
\text {-Recognition, location and traceability of children with special needs in campsites, theme parks, farm } \\
\text { schools, etc. } \\
\text {-Cloud solution to integrate the product offer and new products design } \\
\text {-Interactive itineraries in Biosphere Reserves (communication and information) }\end{array}$ \\
\hline $\begin{array}{l}\text { MARKETING AND } \\
\text { COMMERCIALISAT } \\
\text { ION }\end{array}$ & 7 & 6 & $\begin{array}{l}\text { - Intelligent platform for a personalized tourism contents management } \\
\text { - Technological platform to improve positioning, branding and reputation management in the Rioja } \\
\text { Alta territory } \\
\text { - Website based on a GIS system to check and plan tourist routes in rural areas with mobile devices } \\
\text { (PDA) for rent } \\
\text { - Creation of an innovative wine and gastronomy Gourmet Club } \\
\text { - Mobile App incorporating augmented reality to enhance wine tourism routes' attractiveness } \\
\text { - Immersive tourism experiences for luxury segments in the emerging market of China } \\
\text { - Ecotourism experiences through experiential marketing based on tourist participation }\end{array}$ \\
\hline PROCESS & 2 & 1 & $\begin{array}{l}\text { - Open innovation system for the active user participation with ideas in the SMEs'innovation } \\
\text { processes } \\
\text { - Technological tool to reduce the hotel check-in process time }\end{array}$ \\
\hline $\begin{array}{l}\text { OTHER TYPES: } \\
\text { SOCIAL/ENVIRONM } \\
\text { ENTAL }\end{array}$ & 2 & - & $\begin{array}{l}\text {-Sustainability calculator for tourists and firms in natural protected areas (sustainable awards and } \\
\text { cards, awareness and training, etc.). } \\
\text {-Creation of new tourism products contributing to the marine biodiversity conservation }\end{array}$ \\
\hline TOTAL & 30 & 26 & \\
\hline
\end{tabular}

Source: authors, based on interview with AEI managers and Programme documentation

Organizational innovation: projects reported changes in their internal structure or management, complemented by technological innovations. They especially focused on efficiency and costs (paperless management and reduced purchasing costs), quality improvement (anonymous evaluation systems for hotel clients, and HACCP control points in restaurants), and new ways to relate to customers (new payment systems and loyalty schemes). Some focused on producing better quality data and enhancing knowledge access (e.g. comparisons of competitors' prices).

Product/service innovation: Most projects emphasized the introduction of new services to improve the overall visitor experience; for example, in golf courses (Wi-Fi technology), in natural areas (augmented reality techniques), in hotels (iPads for rent), and in adapting a tourist destination to the needs of tourists with disability (through Near Field Communications).

Marketing and commercialization innovation: These projects focus on customizing experiences, experimenting with new concepts such as experiential marketing or more effective promotion of tourist routes through the use of technologies - both established (Geographical Information System) and pioneer (augmented reality) - applied to new devices (personal digital assistant-PDA, smartphones) in an attempt to make them more interactive, visual and intuitive. Only one project specifically identified a new market (Chinese luxury segment) although this is implicit in the others.

Process innovation: One is dedicated to reducing the production process time in hotels and the other, based on open innovation concepts, allows users to contribute to firm innovation processes. Given the nature of the tourism experience, however, process innovation is implicit in some product/service innovations. 
There has been a predominance of projects with a technological component (26 out of 30, according to project documents), reflecting an inherent technological bias in the Programme with both policymakers and AEI managers agreeing that the innovativeness of a project with a technological component was relatively easier to observe. The dominance of technology in tourism innovation projects has also been identified in EU funding (Hall \& Williams, 2008). These are mostly incremental innovations. They can involve the use of existing technologies, such as GIS systems, in combination with new devices (mobile) or technologies already in use in other fields (Near Field Communication). To some extent this is to be expected because the project evaluation criteria targeted incremental rather than radical innovations.

Despite this reservation, investment in technology has helped to fill sectorial or geographical gaps in innovation, arguably leveraging additional knowledge transfers in individual firms. However, several questions remain unanswered such as whether customer needs are understood (Shaw et al., 2011), and whether customers are eager to use such products and/or pay more for newness. It is also unclear how such innovations will be updated in the context of rapidly changing technologies. One example is the project that rents Personal Digital Assistant devices for use in rural areas. Even when developed in 2009, the mobile device was already obsolete given widespread adoption of smartphones.

\section{Outcomes of innovation policies and implementation barriers}

The Programme funded 59 projects, mostly R\&D projects, followed by networking activities, involving a total budget, 2009-2012, of 5,169,850 Euros (45\% funded by the Programme). However, these data provide information about the most direct input to stimulate the innovation process, but very little about the outcomes in terms of impact or benefit, especially if the inconclusive ending of most of them is considered. To date, only two projects have been commercialized: one was a poorly-received app for use on mobile devices and the other was a mystery guest evaluation system, already terminated without continuity. Two other were in process of being commercialized: the iPad platform for rental in hotels and the real time carbon footprint monitoring system. It might be argued that this could be related to a short time frame given to achieve commercialization but some projects have been in existence for 2-3 years so the lack of tangible innovations is of concern.

The abandonment of 11 AEIs questions the absorptive capacity of the members to recognize, assimilate and apply new knowledge (Cohen \& Levinthal, 1990). The high rate of abandoned projects questions the impact and the efficiency of these processes of R\&D that, by no means, might be considered innovation. An AEI manager (AEI8) openly acknowledges that: "the innovation projects had a limited impact and definitely not that expected in terms of real application", while also suggesting a reformulation of the evaluation criteria to include the "level of implementation and final success of the project". The same manager also recognizes that: "we have worked in projects without real results...because there has been no implementation and they haven't got an impact in the firm profitability, efficiency, etc."

Both, uninitiated projects (viability studies only) and abandoned ones are aspects of concern in terms of effective implementation. This is exemplified by AEI25, which has developed four different projects around a common interest of promoting tourism in Biosphere Reserves, all of which are different from each other and seem not to suppose the continuity, improvement or 
commercialization of the previous ones. The reasons for their abandonment have been common in some instances due to cost of acquisition or, frequently mentioned by interviewees, the lack of usefulness or benefit perceived by the firms. This might be contrasted to the evaluation of the project proposals by Segittur in which the benefit for the AEI members appears blurred, there is weak reasoning about the selected projects and their interest for the members, and dubious estimates about positive outcomes and impact. In part this is due also to a top-down implementation approach by a few AEI members and consultancy companies instead of initiating a process based on consulting firms about their needs. In summary, the Programme has stimulated prototype developments but has not initiated binding criteria to really introduce them in the market.

It is difficult to quantify the outcomes of the Programme, especially in relation to knowledge transfer. In the absence of quantitative data, which would probably have provided a relatively bleak picture in terms of sales, the qualitative information gives a more positive impression of outcomes in terms of changes in social, cognitive and behavioral attitudes towards innovation, and especially cooperation. This also resonates with Novelli et al's (2006) conclusion that process is more important than endpoints. As the Segittur interviewee 1 states:

Sometimes the projects funded were not extremely innovative in their nature but it was worth funding them because of the work and joint management opportunity...The most important innovation generated by this Programme has been in work processes: it has generated innovative structures, modes of collaborative work and discussion, and identified common needs and joint decision making

The main benefits of the AEI Programme more frequently highlighted in the AEI managers' discourses have been the promotion of synergies and cooperation among actors, enhanced innovation awareness, access to funding and the initial impulse to create formal structures to support innovation. The representative of the AEI18 commented that:

The objectives of changing culture, habits and schemes have been met and also of creating a collaborative culture...before, the objective of sitting around a table with the university was inconceivable and now it is possible...

Networking and collaboration have allowed individual entities to access new or complementary competences and technologies but it has been selective, and mostly been between consulting firms, technological suppliers, and private firms, to the exclusion of science and technology agencies, and universities. Networking among AEIs at the annual meetings has also been relatively positive as a means to exchange information and experiences. However, opinions are almost equally divided about the value of joint projects, although Segittur interviewee 1 considered these did offer a positive return: "We have emphasized joint projects and consequently prioritized them in relation to individual ones".

From the interviewee discourses, several facilitators of successful outcomes are identified. The first of these is the inherent features of the AEIs, such as the provision of public subsidies, and the Programme objectives of facilitating collaboration and greater innovation awareness. The Programme has shown that the tourism private sector is highly "stimulable". Secondly, more experienced innovators (evidenced in the interviews) are likely to have satisfactory experiences 
of the Programme. Thirdly, a pre-cluster experience of collaboration was likely to result in a stronger cluster identity, and enhanced collaboration. For example, the Jerez Wine and Brandy Route Association had belonged to the national Wine Routes Product Club. This is, of course, an implied criticism of the artificial creation of many AEI clusters.

In contrast to these positive outcomes, the interviews indicated that 15 of the 26 AEIs were either dissatisfied or very dissatisfied with their performance in relation to their objectives. There were also limitations in the capacity of national policy implementers to evaluate the potential contribution of individual projects to innovation. There are several examples of the Programme initially allocating resources to AEIs with no subsequent activities or with prototype projects that have not been fully implemented. A music cluster (AE13) only elaborated a strategic plan and one project during its first two years, was then inactive and has now disappeared. Similarly, the tourism and innovation cluster in northern central Spain (AE24), which received the largest funding (354.000€), has also disappeared.

Following Hadjimanolis' (2003) classification of obstacles to innovation, combined with the recurrent themes identified in codification and data analysis, the following categories of barriers to implementation and innovation have been established (Table 3), ranked by frequency of appearance in responses. External barriers are diverse, the most important being the economic crisis which affected funding. External sources have been constrained because of public expenditure cuts, as well as the capacity of AEI public bodies to support cluster activities. This has been compounded by tightened credit restrictions which:

affects not only the AEI but also the individual firms capacity to get external funding to improve the product portfolio with more innovative products or improve the firms themselves...credit restrictions are affecting every activity. (AEI23).

Table 3 External and internal barriers to innovation by ranking of importance

\begin{tabular}{ll}
\multicolumn{1}{c}{ External } & Internal (At the AEI level) \\
\hline & 1. Financial (lack of internal \\
$\begin{array}{l}\text { 1. Economic crisis } \\
\text { 2. Tourism sector structural and }\end{array}$ & $\begin{array}{l}\text { funds) } \\
\text { cultural barriers }\end{array}$ \\
$\begin{array}{l}\text { 3. AEI Programme inadequacies } \\
\text { 4. Tourism and innovation }\end{array}$ & 3. Strategy related \\
policy/strategy & \\
\hline
\end{tabular}

Source: authors’ analysis of interviews with AEI managers

The economic situation also affected confidence and, therefore, business attitudes to innovation, given its risky and resource-demanding nature. Public expenditure cuts are critical because public subsidies are important in stimulating $R \& D$ activities, and there are questions about the capacity of the private sector to innovate without support. 
Innovating at no cost [publicly financed] is great but when financing is removed you find there is no interest in continuing with the project... (AEI18)

Structural/cultural barriers are secondary in importance and the most frequently mentioned aspect is the lack of a collaborative culture due to the prevalence of competition and rivalry, limited trust which is essential to knowledge exchange, and little appreciation of the benefits of collaboration. These are classic characteristics of most forms of collaboration in tourism, and are rooted in the prevalence of small firms, a lack of professionalism amongst many entrepreneurs (Hjalager 2012), the particularities of spatial competition in tourism clusters (Weidenfeld et al. 2014) in the face of the complex nature of the tourism experience (Hall \& Williams 2008). Another group of structural barriers is a prevalent conservatism and reluctance to embrace change, reflecting the importance of the institutional features of innovation systems (Edquist 2005): 'Innovation in Spain is conspicuous by its absence and it is a matter of mentality: fear to fail is rooted in the Spanish culture' (AEI21). This barrier is particularly strong among SMEs that have limited resources and familial business cultures. 'This by no means favors innovation which means that radical innovations only happen when there is a generational leap which introduces better qualified managers, with more training' (AEI21). Short termism is also widespread.

The third group of most common barriers are related to the AEI Programme itself, particularly funding evaluation criteria, which are considered to be insufficiently selective and unable to value excellence. This is a critical weakness because of its key role in the implementation process. The representative of AEI26 commented: 'Some AEIs are surviving at the expense of others or at the expense of resources that could be allocated to others'. Five other interviewees shared the opinion that maximizing the number of projects had been prioritized over quality. They argued that other evaluation criteria should have been used such as the priority for the tourism sector, including demand and impact on competitiveness: 'When it comes to developing an innovative project some questions must be asked: is it a project truly demanded by the sector? Has it really got potential to increase competitiveness?' (AEI8)

Tourism innovation policy/strategy barriers include a lack of strategic vision and insufficient prioritization of innovation. This is linked to policy actor perceptions of tourism as a noninnovative sector and limited understanding of tourism innovation.

Our business sector lacks an innovation culture ... a better understanding of what is innovation and what do innovation processes mean. Innovation is everything, it covers many things..[...] innovation is a slightly "prostituted word" so there has been an important work of education in that sense and still a lot of work to do (AEI23)

Amongst the internal barriers, finance or lack of internal funds was identified as crucial by most interviewees. This has two different strands: the failure of cluster members to contribute to the internal AEI budget, or to make a sufficient contribution to guarantee cluster self-financing, and the difficulties of mobilizing private funding.

...There has been funding for idea development that even reached the market but afterwards there has been no funding to diffuse the innovation to allow a massive commercialization, guaranteeing its success (AEI8). 
Second in importance were the structural barriers being the lack of a full time management cluster office in some AEIs, a critical negative factor because most members were unable to allocate extra time to the cluster activities to compensate for the lack of a permanent management structure. Finally, strategy related barriers essentially relate to poorly formulated strategies, either the top-down leadership which failed to stimulate a bottom-up response or inaccurate diagnosis of the innovation needs of firms in individual AEIs. One interviewee (AEI18) related the latter to AEIs tending to work with association representatives, rather than engaging firms directly. Many of these barriers are mutually reinforcing (Mohnen \& Rosa, 2002).

\section{CONCLUSION}

The increasing focus on tourism innovation policies, at different levels (national, regional, local), has often been based more on assertion than on evidence. This paper has sought to present a qualitative and critical analysis of one such policy, the AEI Programme, a rare instance in which tourism has been integrated within an overall national innovation programme (Hall \& Williams, 2008). The paper has sought to overcome some of the weaknesses of traditional approaches, by linking - what have often been fragmented-studies of policy implementation, the process of innovation, and resulting outcomes.

Policy implementation is, to varying degrees, neither a top-down nor a bottom-up process, but a fluid continuum between central guidance and the local autonomy of each AEI to design its own strategies (Pülz \& Treib, 2007). Segittur was appointed to oversee implementation and manage a tourism innovation fund to steer innovation implementation which was expected to be bottom-up, but the implementation process suffered from lack of clarity in the policy guidelines criteria for central funding evaluation of projects. Specifically, the evaluation criteria paid more attention to collaboration than to the other facilitators and barriers to innovation, and probably to some of the specifics characteristics of the tourism industry, such as lack of trust and the difficulty of balancing cooperation versus collaboration in context of within cluster spatial competition (Weidenfeld et al., 2014). In practice, the participation by local actors was uneven, and lacked persistence, so that the contradictions in the implementation model were cruelly exposed once central funding had been withdrawn. This was a fatal weakness given the complex interrelationships amongst the constitutive components of the tourism product or experience. Moreover, an important theoretical contribution of this paper has been to demonstrate that a focus on the local fails to appreciate the significance of polycentricity in institutional arrangements for implementation, especially with respect to the importance of cooperation between multiple authorities that have overlapping jurisdictions and responsibilities. Polycentric theory suggests that to be effective hybrid approaches to policy implementation therefore require all actors to have both capacity and political authority to align strategies and resources towards common goals, as evidenced in the broader social science literature (Fyfe, Johnston Miller \& McTavish, 2009). Studies of tourism policy implementation, including with respect to innovation, therefore need to recognise that non-state actors, including NGOS, private associations and business, have significant roles to play in self-organised innovation regimes, such as geographically proximate clusters, in both policy development and implementation. As the AEI Programme suggests, where actors are included in the policy making process, even at a regional level, thereby increasing their political authority, the likelihood of successful implementation and outcomes is increased. 
The AEI Programme did stimulate innovation-related activity, through fostering collaboration, and funding the creation of strategies and a large number of pilot projects. The innovations were characteristically incremental, organizational and product focused, with a strong technological element; the latter, of course, carried a high risk of rapid obsolescence. Most had not proceeded beyond the pilot stage at the time of writing, but the withdrawal of funding and the closure of 11 AEIs mean that innovations - in the sense of full implementation (commercialization) - are likely, at best, to be modest. At first sight, the policy outcomes were disappointing but a more nuanced evaluation drawing on more recent thinking in the generic literature (Mohnen \& Röller, 2005) recognizes two phases of innovation and, by extension, of innovation policies: first, the decision to innovate and policies which increase the propensity of firms to innovate, and secondly the intensity of innovation activity. Whether by design, or more likely by accident, the AEI Programme has been more effective at fostering the propensity than the intensity of innovation. Thus, although several AEIs have disappeared, without significant innovation achievements, 21 have survived after passing through a difficult period, as is typical of the partnership life cycle (Caffyn, 2000). Such results raise significant questions as to what actually constitutes success in policy interventions, how it is evaluated and the time frame of the evaluation (Hall, 2014)

Looking to the future, there are a number of lessons for tourism innovation policies, and for researchers. First, any policy process is inevitably a hybrid combination of top-down and bottomup approaches. In this case insufficient attention was given to the capacities and political authority of actors which would have enabled greater collaboration towards common strategic goals. This example therefore highlights that in multi-level implementation, the strength of polycentric institutional arrangements is a critical determinant of policy success (Andersson \& Ostrom, 2008). To increase the likelihood of achieving desired policy outcomes, actors need to be included in both policy formulation as well as policy implementation as this increases levels of political authority and capacity. Furthermore, there is a need to integrate research across the policy domains, innovation processes and innovation outcomes, which has been a particular contribution of this paper. Secondly, tourism policies are more likely to be effective when grounded in an understanding of tourism innovation systems and targeted innovation measures that account for the different sub-sectoral demands on tourism businesses. There is often, as in this study, a vicious circle of mutually-reinforcing barriers which inhibit innovation and a systemic approach is required to overcome these (Mohnen \& Rosa, 2002; Galia \& Legros, 2004). Such an approach would address not only knowledge transfer, but also finance, governance, human capital and demand. The Spanish case also highlighted that barriers linked to the specificities of the tourism sector should be addressed at the policy design stage. Some barriers are inherent in the specific innovation climate of a country but others are specific to the tourism sector. This emphasizes that tourism can benefit from integration into general national innovation frameworks, and highlights the need for more horizontal innovation policies. Thirdly, differentiated innovation policies, dealing with specific innovation barriers in different types of regions are required (Tödtling \& Trippl, 2005), rather than serial policies, or casual transfer of ideal models. Tourism innovation policies can not just replicate the proven successes of more generic innovation policies, but must address the specificities of the tourism sector and of destinations, including the predominance of SMEs, the complex inter-related nature of the tourism product and tourism experience, the compelling logic of the uno-acto principle which often results in short termism (see also OECD, 2005b), and the significance of project ecologies 
(the roles of the environment, consumer inter-relationships, and host-guest relationships).Finally, although innovation is increasingly seen as the holy grail of tourism development, there are no quick-fix solutions to innovation deficits, and policies and funding require appropriate time frames, and industrial and political commitment. All these observations underline the need to fill in critical gaps in our fragmented understanding of tourism innovation policies.

\section{Acknowledgments}

The research paper has been supported by the Spanish National R\&D\&I Plan 2008-2011 (CSO2011-26396). The authors are grateful to the state-owned company "Innovation Management and Tourism Technologies, SEGITTUR" for their generous support and data provision. Isabel Rodriguez thanks the University of Alicante who funded her visit to the University of Surrey, facilitating the authors' collaboration.

\section{References}

Adams, R., Tranfield, D., \& Denyer, D. (2006). Innovation Types: Configurations of Attributes as a Basis for Innovation Classification, Working Paper 46. London: Advanced Institute of Management Research.

Alsos, G.A., Eide, D., Madsen, E.L. (Eds.) (2014). Handbook of Research on Innovation in Tourism Industries. Cheltenham: Edward Elgar.

Amin, A. (2002). Spatialities of globalization. Environment and Planning A, 34, 385-399.

Andersson, K., \& Ostrom, E. (2008). Analyzing decentralized resource regimes from a polycentric perspective. Policy Sciences, 41(1), 71-93.

Asheim, B. T., Boschma, R., \& Cooke, P. (2011). Constructing Regional Advantage: Platform policies based on related variety and differentiated knowledge bases. Regional Studies, 45(7), 893-904.

Barrett, S. and Fudge, C. (Eds.) (1981). Policy and action: essays on the implementation of public policy. London: Methuen.

Birkland, T. (2005). An introduction to the policy process: Theories, concepts and models of policy making. Armonk: M.E. Sharpe.

Benneworth, P., Danson, M., Raines, P., \& Whittam, G., 2003. Confusing cluster? Making sense of the cluster approach in theory and practice. European Planning Studies, 11, 511-520. 
Braczyk, H., Cooke, P., \& Heidenreich, M. (Eds.). (1998). Regional innovation systems: the role of governances in a globalized world. London: Routledge.

Caffyn, A. (2000). Is there a tourism partnership life cycle?, in B. Bramwell \& B. Lane (Eds.), Tourism collaboration and partnerships: Politics, partnerships and sustainability (pp. 200-229). London: Channel View.

Cohen, W., \& Levinthal, D. (1990). Absorptive-capacity - a new perspective on learning and innovation. Administrative Science Quarterly, 35(1), 128-152.

Diez, M. (2001). The evaluation of regional innovation and cluster policies: towards a participatory approach. European Planning Studies 9(7): 907-923.

Edquist, C. (2001) The systems of innovation approach and innovation policy: an account of the state of the art, lead paper presented at the DRUID Conference Aalborg, 12-15 June 2001, Theme F: "National systems of innovation, institutions and public policies", Aalborg: DRUID.

Edquist, C. (2005). Systems of innovation: perspectives and challenges. In J. Fagerberg, D. Mowery \& R. Nelson (Eds.), The Oxford handbook of innovation (pp. 599-631). Oxford: Oxford University Press.

Eurostat (2014). Community innovation system: description of data set.

Eurostat, http://epp.eurostat.ec.europa.eu/portal/page/portal/microdata/cis, accessed 30 July 2014.

Faludi, A. (Ed.) (2008). European spatial research and planning. Cambridge, MA: Lincoln Institute of Land Policy.

Flanagan, K., Uyarra, E., \& Larangja, M. (2011). Reconcepturalising the 'policy mix' for innovation. Research Policy, 40(5), 702-713.

Fromhold-Eisebith, M., \& Eisebith, G. (2005). How to institutionalize innovative clusters? Comparing explicit top-down and implicit bottom-up approaches. Research Policy, 34, 12501268.

Fyfe, G., Johnston Miller, K., \& McTavish, D. (2009), 'Muddling through’ in a devolved polity: implementation of equal opportunities policy in Scotland. Policy Studies, 30, 203-219.

Galia,F., \& Legros, D. (2004). Complementarities between obstacles to innovation: evidence from France, Research Policy, 33(8), 1185-1199.

Gertler, M., Wolfe, D., \& Garkut, D. (2000). No place like home? The embeddedness of innovation in a regional economy, Review of International Political Economy, 7(4), 688-718.

Hadjimanolis, A. (2003). The barriers approach to innovation. In L. Shavinina (Ed.), The International Handbook on Innovation, (pp. 559-573). Oxford: Elsevier. 
Hall, C.M. (2005). Rural wine and food tourism cluster and network development. In D. Hall, I. Kirkpatrick, \& M. Mitchell (Eds.), Rural Tourism and Sustainable Business (pp. 149-164).

Clevedon: Channel View.

Hall, C.M. (2008). Tourism planning, $2^{\text {nd }}$ ed., Harlow: Prentice Hall.

Hall, C.M. (2009a). Innovation and tourism policy in Australia and New Zealand: never the twain shall meet? Journal of Policy Research in Tourism, Leisure and Events, 1(1), 2-18.

Hall, C.M. (2009b). Archetypal approaches to implementation and their implications for tourism policy, Tourism Recreation Research, 34(3), 235-245.

Hall, C.M. (2011). A typology of governance and its implications for tourism policy analysis. Journal of Sustainable Tourism, 19(4-5), 437-457.

Hall, C.M. (2014). Tourism and social marketing. Abingdon: Routledge.

Hall, C.M., \& Williams, A. M. (2008). Tourism and innovation. London: Routledge.

Hanf, K., \& O’Toole, L. (1992). Revisiting old friends: networks, implementation structures and the management of inter-organizational relations. European Journal of Political Research, 21, $163-180$.

Hjalager, A.M. (2002). Repairing innovation defectiveness in tourism. Tourism Management, 23, 465-474.

Hjalager, A.M. (2010). A review of innovation research on tourism. Tourism Management, 31, 112

Hjalager, A.M. (2012). Innovation policies for tourism. International Journal of Tourism Policy, 4(4): 336-355.

Hjern, B. (1982). Implementation research: The link gone missing. Journal of Public Policy, 2, 301-308.

Hupe, P.L. (2011). The thesis of incongruent implementation: revisiting Pressman and Wildavsky. Public Policy and Administration, 26(1), 63-80.

Hupe, P.L. (2014). What happens on the ground: Persistent issues in implementation research. Public Policy and Administration, 29(2), 164-182.

Ioannides, D., \& Petersen, T. (2003). Tourism non-entrepreneurship in peripheral destinations: a case study of small and medium enterprises on Bornholm, Denmark, Tourism Geographies, 5(4), 408-305.

Jacob, M., Tintoré, J., Aguiló, E., Bravo, A., \& Mulet, J. (2003). Innovation in the tourist sector: Results from a pilot study in the Balearic Islands. Tourism Economics, 9(3), 279-295. 
Jackson, J., \& Murphy, P. (2006). Clusters in regional tourism: An Australian case. Annals of Tourism Research, 33(4), 1018-1035.

Kanter, R. M. (1983). The Change Masters, London: Unwin.

Longhi, C., \& Keeble, D. (2000). High technology clusters and evolutionary trends in the 1990s. In D. Keeble \& F. Wilkinson (Eds.), High technology Clusters, Networking and Collective Learning in Europe (pp. 21-56). Aldershot: Ashgate.

Lundvall, B. (2007). National innovation systems - analytical concept and development tool. Industry and Innovation, 14(1), 95-119.

Majone, G. (1989). Evidence, argument and persuasion in the policy process. New Haven: Yale University Press.

Major, E., \& Cordey-Hayes, M. (2003). Encouraging innovation in small firms through externally generated knowledge. In L. Shavinina (Ed.), International Handbook on Innovation (pp. 667-679). Oxford: Elsevier.

Malmberg, A., \& Maskell, P. ( 2002). The elusive concept of localization economies: towards a knowledge-based theory of spatial clustering. Environment and Planning A, 34, 429-449.

Mei, X. Y., Arcodia, C., \& Ruhanen, L. (2013). The national government as the facilitator of tourism innovation: evidence from Norway. Current Issues in Tourism, DOI: 10.1080/13683500.2013.822477.

Michael, E.J. with Frisk, L., Hall, C.M., Johns, N., Lynch, P., Mitchell, R., Morrison, A. \& Schreiber, C. (2006). Micro-clusters and networks: The growth of tourism. Oxford: Elsevier.

Mohnen, P., \& Röller, L. H. (2005). Complementarities in innovation policy. European Economic Review, 49(6), 1431-1450.

Mohnen, P., \& Rosa, J. (2002). Barriers to innovation in service industries in Canada. In M. Feldman \& N. Massard (Eds.), Institutions and Systems in the Geography of Innovation (pp. 231250). Boston: Kluwer Academic Publishers.

Newig, J., \& Koontz, T. (2014). Multi-level governance, policy implementation and participation: the EU's mandated participatory planning approach to implementing environmental policy. Journal of European Public Policy, 21(2), 248-267.

Nordin, S. (2003). Tourism Clusters and Innovation - Paths to Economic Growth and Development, Östersund: European Tourism Research Institute.

Novelli, M., Schmitz, B., \& Spencer, T. (2006). Networks, clusters and innovation in tourism: a UK Experience. Tourism Management, 27(6), 1141-1152. 
OECD (2001). Innovative clusters: drivers of national innovation systems. Paris: OECD

OECD (2005a). Oslo Manual: Guidelines for collecting and interpreting innovation data, 3rd Edition, Paris: OECD Publishing.

OECD (2005b). Governance of innovation systems, Synthesis Report: Volume 1. Paris: OECD.

OECD (2006). Innovation and growth in tourism. Paris: OECD

OECD (2009). Policy Responses to the Economic Crisis: Investing in Innovation for Long-Term Growth. Paris: OECD.

OECD (2012a). Green innovation in tourism services. Paris: OECD.

OECD (2012b). Policy framework for policy coherence for development. Paris: OECD

Ostrom, E. (2005). Understanding institutional diversity. Princeton: Princeton University Press.

Ostrom, V., Tiebout, C.M., \& Warren, R. (1961). The organization of government in metropolitan areas: A theoretical inquiry. American Political Science Review, 55(4), 831-842.

Plummer, R., Kulczycki, C., \& Stacey, C. (2006). How are we working together? A framework to assess collaborative arrangements in nature-based tourism. Current Issues in Tourism, 9(6), 499515.

Porter, M. (2000). Locations, clusters and company strategy. In G.L. Clark, M.S. Gertler \& M. Feldman (Eds.), Oxford handbook of economic geography (pp. 253-274). Oxford: Oxford University Press.

Pülzl, H., \& Treib, O. (2007). Policy implementation. In F. Fischer, G. Miller \& M. Sidney (Eds.), Handbook of public policy analysis: Theory, politics and methods (pp. 89-108). Boca Raton: CRC Press.

Sabatier, P. A. (1986). Top-down and bottom-up approaches to implementation research: a critical analysis and suggested synthesis. Journal of Public Policy, 6, 21-48.

Secretaría General de Turismo. (2007). Plan del Turismo Español. Horizonte 2020. Documento ejecutivo. Madrid. Ministerio de Industria, Turismo y Comercio.

Shaw, G., Bailey, A., \& Williams, A. (2011). Aspects of service-dominant logic and its implications for tourism management: Examples from the hotel industry. Tourism Management, 32(2), 207-214.

Smith, K. (2005). Measuring innovation. In J. Fagerberg, D. Mowery \& R. Nelson (Eds.), The Oxford handbook of innovation (pp. 599-631). Oxford: Oxford University Press. 
Strauss, A., \& Corbin, J. (1990). Basics of qualitative research: Grounded theory procedures and techniques. Newbury Park: Sage.

Toonen, T. (2010). Resilience in public administration: the work of Elinor and Vincent Ostrom from a public administration perspective. Public Administration Review, 70(2), 193-202.

Tödtling, F., \& Kaufmann, A. (1999). Innovation systems in regions of Europe-a comparative perspective. European Planning Studies, 7, 699-717.

Tödtling, F., \& Trippl, M. (2005). One size fits all?: Towards a differentiated regional innovation policy approach. Research Policy, 34(8), 1203-1219.

Weidenfeld, A., Butler, R. \& Williams, A. M. (2011). The role of clustering, cooperation and complementarities in the visitor attraction sector. Current Issues in Tourism, 14(7), 595-629.

Weidenfeld, A., \& Hall, C.M. (2014). Tourism in the development of regional and sectoral innovation systems. In A. Lew, C.M. Hall \& A. Williams (Eds.), The Wiley Blackwell Companion to Tourism (pp. 578-588). Oxford: Wiley-Blackwell.

Weidenfeld, A., Williams, A., \& Butler, R. (2010). Knowledge transfer and innovation among attractions. Annals of Tourism Research, 37(3), 604-626.

Weidenfeld, A., Williams, A. M. \& Butler, R. W. (2014). Spatial competition and agglomeration in the visitor attraction sector. Service Industries Journal, 34(1), 175-195

Wolfe, D.A., \& Gertler, M. (2004). Clusters from the inside and out: local dynamics and global linkages. Urban Studies, 41, 1071-1093.

Zapata, M.J., \& Hall, C.M. (2012). Public-private collaboration in the tourism sector: balancing legitimacy and effectiveness in Spanish tourism partnerships, Journal of Policy Research in Tourism, Leisure and Events, 4(1), 61-83. 